\title{
Correlation of Hypoxic Ischemic Encephalopathy Stages with Clinical Variables
}

\author{
Manchala Chandra Sekhar ${ }^{\circledR}$ \\ Assistant Professor, Department of Pediatrics, Maheshwara Medical College \& Hospital, Patancheru, Medak, Telangana, India.
}

\section{Abstract}

Background:Injury to the CNS related with perinatal asphyxia is referred to as Hypoxic-Ischemic Encephalopathy which is the utmost severe neurological condition that arises in perinatal periods. The aim is to assess clinical variables with hypoxic-ischemic encephalopathy stages. Subjects and Methods: A clinical study of 42 new borns asphyxiated were assessed clinically of these asphyxiated neonates was carried out using Sarnath and Sarnath Staging of HIE. The association between asphyxia at birth and HIE has been examined. Results: In the present study, maternal history, gestational age, and mode of delivery were found to be not significant and do not correlate with the severity of HIE. Sarnath and Sarnath clinical scoring for neurobehavioral signs and symptoms $13(31 \%)$ had reveal of HIE stage $-1,14(33 \%)$ are of stage -2 and severe HIE (HIE-III) common, seen in 15cases (36\%). The correlation of non-stress test (NST), Meconium staining was more in stage-3 in HIE stages and statistically significant. Conclusion: During the diagnosis and treatment of HIE patients, analysis of clinical variables will improve the objectivity of newborn assessment and evaluation and early start of care.

Keywords: Hypoxic Ischemic Encephalopathy, Sarnath, Sarnath clinical scoring

Corresponding Author: Manchala Chandra Sekhar, Assistant Professor, Department of Pediatrics, Maheshwara Medical College \& Hospital, Patancheru, Medak, Telangana, India.

E-mail: drmanchala@gmail.com

Received: 20 May 2020

Revised: 25 June 2020

Accepted: 2 July 2020

Published: 10 October 2020

\section{Introduction}

Perinatal asphyxia attribute to a state in the $1^{\text {st }}$ and $2^{\text {nd }}$ phases of labor in which compromised circulation contributes to fetal hypercarbia, hypoxemia leading to metabolic acidosis. ${ }^{[1]}$ A significant component for Perinatal asphyxia is perinatal and neonatal mortality. ${ }^{[2]}$ most significant long-term result of birth asphyxia is cerebral palsy which can be followed by intellectual under development, epilepsy disease, or any visual or auditor, cognitive and sensory disorders. It is the $5^{\text {th }}$ big cause of child deaths under 5 years of age ( 8.5 percent) after pneumonia, neonatal infections, diarrhea and hurdle of premature birth. ${ }^{[3]}$

Dr. Virginia Apgar developed a scoring system which was a quick practice of evaluating the newborn infant's clinical condition at the age of 1 st minute. ${ }^{[4]}$ It was conceived as a guide to the need for newborn resuscitation, and evolved as an objective tool that assessed five signs of physiological adaptation. This scoring system was fast gaining nearuniversal acceptance. However, the Apgar score can somewhat assess mortality, it's not a method that can be used only for the assessment of living infants' neurological outcomes. Most childbirths in developed countries typically occur at home, with untrained birth attendants attending. Lack of execution and retention of oxygen. Immediately after birth, serious fetal hypoxia or ischemia may develop as encephalopathy in the infant, called Hypoxic Ischemic Encephalopathy (HIE). The fetus with a substantial episode of hypoxia is at risk of developing HIE which can result in neonatal mortality or irreversible motor which mental disability. In India, 8.4 percent of inborn babies have less than 7 percent 1 minute Apgar score and 1.4 percent put up from HIE. ${ }^{5]}$

Nevertheless, in many neonatal units in developed countries such as India, these modalities are not readily accessible and thus the centers depend heavily on clinical evaluation and scoring mechanisms to assess the neurological injury. Our study aims to consider the occurrence of HIE in asphyxiated newly born neonate based on the existing method of neurological scoring and aims to assess the estimation of the grading of neurological damage depending on the seriousness of the sustained asphyxia. 


\section{Subjects and Methods}

It is carried out in the neonatal unit of the Department of Pediatrics in association with the Department of Obstetrics and Gynaecology. This is a prospective study that included 42 neonates selected as per inclusion criteria.

\section{Inclusion criteria:}

Term Babies admitted to NICU with a score of Apgar 6 or less at birth, at 5 minutes. Intrapartum signs of fetal distress and amniotic fluid stained with meconium.

Positive pressure venting condition of $>1$ min Moderate, moderate, or extreme HIE as described by staging Sarnat and Sarnat.

\section{Exclusion criteria:}

Suspected metabolic disease, congenital malformations, fever within 2 months before delivery, Those born to mothers having HTN, DM, toxemia of pregnancy.

Total obstetric history was collected, and after birth examination of the babies was carried out. The neonatal clinical course was prospectively followed up and predesigned proforma data was recorded. For all infants, written informed parental consent was obtained before entry into the study, approved by the ethical committee.

HIE was classified as mild (grade I), moderate (grade II) or severe (grade III) by H.B.

Sarnat, M.S and Sarnat. ${ }^{[6]}$ Assessment of Clinical encephalopathy was performed 24 to 48 hours after birth.

Microsoft Excel and SPSS applications performed sufficient data entry and mathematical analysis. Number and percentage are presented as categorical variables. The Chi-square test compares the association between two or more categorical variables. A statistically relevant $p$-value of $<0.05$ has been taken.

\section{Results}

Among 42 newborns 28 (66.7\%) were males and 14 (33.3\%) were females and $24(57.2 \%)$ were term and $17(40.4 \%)$ were post-term as per gestational age. As per the mode of delivery, most of the cases are of LSCS with 17 cases (40.4\%) and newborns born to primigravida are more with 27 cases $(64.3 \%)$.

Sarnath and Sarnath clinical scoring for neurobehavioral signs and symptoms 13 (31\%) had evidence of HIE stage $-1,14$ (33\%) are of stage -2 and severe HIE (HIE-III) common, seen in 15 cases $(36 \%)$.

Clinical variables are not significant in HIE I and II stages.

The correlation of non-stress test (NST) whether reactive or non-reactive which is an indicator of fetal distress affects HIE

\begin{tabular}{|c|c|c|c|}
\hline \multicolumn{4}{|c|}{ Table 1: Demographic } \\
\hline Gender & \multicolumn{2}{|c|}{ Number of cases } & Percentages \\
\hline Males & \multicolumn{2}{|l|}{28} & 66.7 \\
\hline Females & \multicolumn{2}{|l|}{14} & 33.3 \\
\hline \multicolumn{4}{|l|}{ Gestational age } \\
\hline Preterm & \multicolumn{2}{|l|}{1} & 2.4 \\
\hline Term & \multicolumn{2}{|l|}{24} & 57.2 \\
\hline Post-term & \multicolumn{2}{|l|}{17} & 40.4 \\
\hline \multicolumn{4}{|l|}{ Mode of delivery } \\
\hline $\begin{array}{l}\text { Normal vaginal } \\
\text { delivery }\end{array}$ & \multicolumn{2}{|l|}{13} & 31 \\
\hline $\begin{array}{l}\text { With instru- } \\
\text { mentation }\end{array}$ & \multicolumn{2}{|l|}{12} & 28.6 \\
\hline $\begin{array}{l}\text { Lower seg- } \\
\text { ment cesarean } \\
\text { section }(\text { LSCS) }\end{array}$ & \multicolumn{2}{|l|}{17} & 40.4 \\
\hline \multicolumn{4}{|l|}{ Maternal gravida } \\
\hline Primi & \multicolumn{2}{|l|}{27} & 64.3 \\
\hline Multi & \multicolumn{2}{|l|}{15} & 35.7 \\
\hline \multicolumn{4}{|l|}{ Table 2: Clinical } \\
\hline \multicolumn{2}{|c|}{$\begin{array}{l}\text { Meconium stained } \\
\text { amniotic fluid }\end{array}$} & $\begin{array}{l}\text { Number of } \\
\text { cases }\end{array}$ & Percentages \\
\hline \multicolumn{2}{|l|}{ No staining } & 17 & 40.4 \\
\hline \multicolumn{2}{|l|}{ Stained } & 25 & 59.6 \\
\hline \multicolumn{4}{|l|}{ Nonstress test } \\
\hline \multicolumn{2}{|l|}{ Reactive } & 13 & 31 \\
\hline \multicolumn{2}{|l|}{ Nonreactive } & 29 & 69 \\
\hline \multicolumn{4}{|l|}{ Outcome } \\
\hline Discharge & & 39 & 92.9 \\
\hline Death & & 3 & 7.1 \\
\hline
\end{tabular}

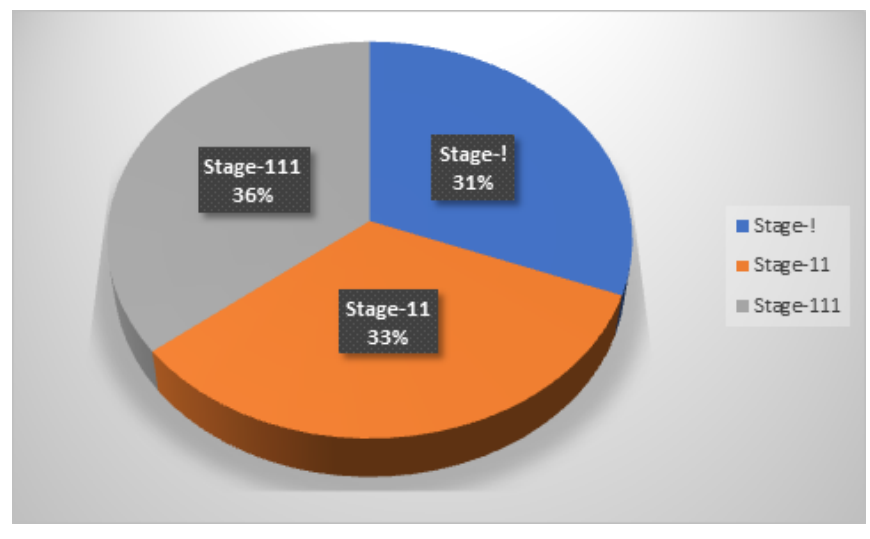

Figure 1: HIE 
Table 3: Correlation of clinical variables with HIE I and II stages in the study

\begin{tabular}{|llll}
\hline Variables & Stage-I & Stage-2 & P-Value \\
\hline Gestational age & N (\%) & N (\%) & \\
\hline Preterm & $1(7.7 \%)$ & 0 & $>0.05$ \\
\hline Term & $8(61.5 \%)$ & $7(50 \%)$ & \\
Post-term & $4(30.8 \%)$ & $7(50 \%)$ & $>0.05$ \\
\hline Mode of Delivery & & $5(35.7 \%)$ & \\
Normal vaginal delivery & $4(30.7 \%)$ & $4(28.6 \%)$ & \\
With instrumentation & $3(23.1 \%)$ & $5(35.7 \%)$ & \\
\hline Lower segment cesarean section & $6(46.2 \%)$ & $9(64.3 \%)$ & \\
Maternal Gravida & & $5(35.7 \%)$ & $>0.05$ \\
\hline Primi & $8(61.5 \%)$ & & \\
Multi & $5(38.5 \%)$ & $6(42 . \%)$ & $>0.05$ \\
\hline Meconium stained amniotic fluid & & $8(57.1 \%)$ & \\
No staining & $5(38.5 \%)$ & $7(50 \%)$ & \\
\hline Stained & $8(61.5 \%)$ & $7(50 \%)$ & \\
\hline Nonstress test & $6(46.2 \%)$ & $13(92.8 \%)$ & \\
\hline Reactive & $7(53.8 \%)$ & $1(7.1 \%)$ & \\
\hline Non reactive & $13(100 \%)$ & & \\
\hline Outcome & 0 & & \\
\hline Discharge & & & \\
Death & & & \\
\hline
\end{tabular}

stages among the cases and it was found to be statistically significant.

Meconium staining was more in stage-2 in HIE stages and statistically significant.

The correlation of outcome with HIE stages among the cases and it was found that $13.3 \%$ death and all were with HIE stage 3 and was statistically significant.

The correlation of non-stress test (NST) whether reactive or non-reactive which is an indicator of fetal distress affects HIE stages among the cases and it was found to be statistically significant.

Meconium staining was more in stage-3 in HIE stages and statistically significant.

The correlation of outcome with HIE stages among the cases and it was found that $33.3 \%$ death and all were with HIE stage3 and was statistically significant.

\section{Discussion}

HIE is serious enough to inflict irreversible brain damage, is prevailing retrospectively characterized by consensus-based standards, which together represent a psychiatric condition defining a causal mechanism of HIE. The mechanism provides proof of fetal complications in the last hours prior to delivery, distress at delivery and require for resuscitation, extreme metabolic acidosis, neonatal health and diagnostic symptoms of acute neurological disorders, indications of other processes dysfunction, and absence of other causes of neonatal encephalopathy. ${ }^{[7]}$ Sarnat and Sarnat's three step categorization of HIE is widely used; the most serious period in periodic exams, between $1 \mathrm{~h}$ and 7 days of life, is the most effective step in prediction and follow-up decisions. ${ }^{[6]}$

This study aimed to consider the occurrence of HIE in asphyxiated newborns placed on the existing neurological scoring system and to compare the incidence of hypoxic-ischemic encephalopathy in different infant, perinatal and maternal variables in asphyxiated newborns. Fifty asphyxiated newborns have been examined and both follow the requirements for inclusion. Among these asphyxiated newborns born in our hospital, Among 42 newborns 28(66.7\%) were males and 14 $(33.3 \%)$ were females, and $24(57.2 \%)$ and as per gestation; term and 17 (40.4\%) were post-term.

Ritambhara Lohan et al study males were 30 cases $(60 \%)$ and females were 20 cases (40\%) and as per gestation, 31 
Table 4: Correlation of clinical variables with HIE II and III stages in the study

\begin{tabular}{|c|c|c|c|}
\hline \multirow[t]{2}{*}{ Variables } & Stage-2 & Stage-3 & P-value \\
\hline & $\mathbf{N}(\%)$ & $\mathbf{N}(\%)$ & \\
\hline \multicolumn{4}{|l|}{ Gestational age } \\
\hline Preterm & 0 & 0 & \\
\hline Term & $7(50 \%)$ & $9(60 \%)$ & $>0.05$ \\
\hline Post term & $7(50 \%)$ & $6(40 \%)$ & \\
\hline \multicolumn{4}{|l|}{ Mode of Delivery } \\
\hline Normal vaginal delivery & $5(35.7 \%)$ & $4(26.7 \%)$ & $>0.05$ \\
\hline With instrumentation & $4(28.6 \%)$ & $3(20 \%)$ & \\
\hline $\begin{array}{l}\text { Lower segment cesarean } \\
\text { section }\end{array}$ & $5(35.7 \%)$ & $8(53.4 \%)$ & \\
\hline \multicolumn{4}{|l|}{ Maternal Gravida } \\
\hline Primi & $9(64.3 \%)$ & $10(66.7 \%)$ & $>0.05$ \\
\hline Multi & $5(35.7 \%)$ & $5(33.3 \%)$ & \\
\hline \multicolumn{4}{|c|}{ Meconium stained amniotic fluid } \\
\hline No staining & $6(42 . \%)$ & $5(33.3 \%)$ & \\
\hline Stained & $8(57.1 \%)$ & $10(66.7 \%)$ & $<0.05$ \\
\hline \multicolumn{4}{|l|}{ Nonstress test } \\
\hline Reactive & $7(50 \%)$ & $5(33.3 \%)$ & \\
\hline Nonreactive & $7(50 \%)$ & $10(66.7 \%)$ & \\
\hline \multicolumn{4}{|l|}{ Outcome } \\
\hline Discharge & $13(92.8 \%)$ & $13(86.7 \%)$ & $<0.05$ \\
\hline Death & $1(7.1 \%)$ & $2(13.3 \%)$ & \\
\hline
\end{tabular}

cases $(62 \%)$ were term and 19 cases $(38 \%)$ preterm. ${ }^{[8]}$ Dalal A et al in their study had 168 cases(52.5\%) males and 152 cases $(47.5 \%)$ females and $87 \%$ were term neonates and $13 \%$ preterm neonates. ${ }^{[9]}$

In the present study used Sarnath and Sarnath clinical scoring for neurobehavioral signs and symptoms 13 (31\%) had evidence of HIE stage $-1,14(33 \%)$ are of stage -2 and severe HIE (HIE-III) common, seen in 15 cases(36\%). Which is by Ritambhara Lohan et al study out of 21 cases of HIE, 5 (23.81\%) were HIE-I, 7 (33.33\%) HIE-II, and 9 (42.86\%) HIEIII. ${ }^{[8]}$

In comparison with HIE -II to III and HIE -I to III are in a correlation of non-stress test (NST) whether reactive or nonreactive which is an indicator of fetal distress affects HIE stages among the cases and it was found to be statistically significant. (P-value of $<0.001$ )

Meconium staining was also statistically significant. The correlation of outcome with HIE stages among the cases and it was found that $33.3 \%$ death and all were with HIE stage 3 and was statistically significant. In the study Priyanka Akka et al non-reactive nonstress test (NST) and thick meconium staining of the liquor found to be statistically significant. ${ }^{[10]}$ Milsom et al . reported only 1 antepartum factor but 6 intrapartum factors separately correlated with low Apgar scores in a populationbased case control analysis of 227 premature babies who had low Apgar scores not due to maternal anesthesia, congenital malformations, or chromosomal abnormalities. ${ }^{[11]}$

The involvement of meconium and a cesarean birth is linked to HIE in the group of 75 babies that eventually experienced encephalopathy. Several authors correlated poorly Apgar scores with meconium contaminated amniotic fluids. ${ }^{[12]}$ Throughout these tests, when meconium was present, the frequency of low one and five minute Apgar score was nearly 2 times greater. Ash AK et al indicated that meconium contaminated amniotic fluids may indicate underlying acute or chronic fetal hypoxia with adverse perinatal outcomes. ${ }^{[13]}$ In conclusion, consideration of clinical variables during the diagnosis and treatment of HIE cases that boost the objectivity of newborn evaluation and monitoring and early start of care. HIE scoring methods were used in many trials. Portman et al. established a statistical the score of early morbidity and mortality. ${ }^{[14]}$ Although others established a score that was related to longterm outcome. HIE's most commonly adopted classification is Sarnat and Sarnat, ${ }^{[6]}$ 
Table 5: Correlation of clinical variables with HIE I and III stages in the study

\begin{tabular}{|c|c|c|c|}
\hline \multirow[t]{2}{*}{ Variables } & Stage-I & Stage-3 & P-Value \\
\hline & $\mathbf{N}(\%)$ & $\mathbf{N}(\%)$ & \\
\hline \multicolumn{4}{|l|}{ Gestational age } \\
\hline Preterm & $1(7.7 \%)$ & 0 & \\
\hline Term & $8(61.5 \%)$ & $9(60 \%)$ & $>0.05$ \\
\hline Post term & $4(30.8 \%)$ & $6(40 \%)$ & \\
\hline \multicolumn{4}{|l|}{ Mode of Delivery } \\
\hline $\begin{array}{l}\text { Normal vaginal } \\
\text { delivery }\end{array}$ & $4(30.7 \%)$ & $4(26.7 \%)$ & $>0.05$ \\
\hline $\begin{array}{l}\text { With instrumenta- } \\
\text { tion }\end{array}$ & $3(23.1 \%)$ & $3(20 \%)$ & \\
\hline $\begin{array}{l}\text { Lower segment } \\
\text { cesarean section }\end{array}$ & $6(46.2 \%)$ & $8(53.4 \%)$ & \\
\hline \multicolumn{4}{|l|}{ Maternal Gravida } \\
\hline Primi & $8(61.5 \%)$ & $10(66.7 \%)$ & $>0.05$ \\
\hline Multi & $5(38.5 \%)$ & $5(33.3 \%)$ & \\
\hline \multicolumn{4}{|c|}{ Meconium stained amniotic fluid } \\
\hline No staining & $5(38.5 \%)$ & $5(33.3 \%)$ & $<0.05$ \\
\hline Stained & $8(61.5 \%)$ & $10(66.7 \%)$ & \\
\hline \multicolumn{4}{|l|}{ Nonstress test } \\
\hline Reactive & $6(46.2 \%)$ & $5(33.3 \%)$ & $<0.05$ \\
\hline Non reactive & $7(53.8 \%)$ & $10(66.7 \%)$ & \\
\hline \multicolumn{4}{|l|}{ Outcome } \\
\hline Discharge & $13(100 \%)$ & $13(86.7 \%)$ & $<0.05$ \\
\hline Death & 0 & $2(13.3 \%)$ & \\
\hline
\end{tabular}

using EEG and other laboratory criteria that may not be possible in a developed world neonatal unit. In another study, a comprehensive follow-up of neurodevelopment was conducted on 167 children with an HIE diagnosis. In that study, a larger proportion of handicapped infants are diagnosed with neonatal convulsion. ${ }^{[15]}$ While neonates that experienced convulsions in this research group are at an elevated risk of damage from neurodevelopment and required close monitoring. A study conducted by Finner et al. to determine causes impacting HIE outcome in term infants showed that variables that were strongly associated with outcome included the Sarnat grading and obdurate seizure frequency. ${ }^{[16]}$ It was observed that there was no correlation between Apgar score 1 or $5 \mathrm{~min}$, requirement of ventilation, EEG, seizure frequency and subsequent outcome. This study coherent with the earlier report that the result of neurodevelopment of infants with HIE is consistent with the Sarnat stage of encephalopathy and it is suspected that the occurrence of seizures is a risk of dysfunction of neurodevelopment.

\section{Conclusion}

During the diagnosis and treatment of HIE patients, analysis of clinical variables will improve the objectivity of newborn assessment and evaluation and early start of care.

\section{References}

1. Morales P, Bustamante D, Espina-Marchant $\mathrm{P}, \mathrm{Neira-Peña} \mathrm{T}$, Gutiérrez-Hernández MA, Allende-Castro C. Pathophysiology of perinatal asphyxia: can we predict and improve individual outcomes? EPMA J . 2011;2(2):211-230. Available from: https://dx.doi.org/10.1007/s13167-011-0100-3.

2. Padayachee N, Ballot DE. Outcomes of neonates with perinatal asphyxia at a tertiary academic hospital in Johannesburg, South Africa. S Afr J Child Health. 2013;7(3):89-89. Available from: https://dx.doi.org/10.7196/sajch.574.

3. Angiti RR, Kumar P. Follow up of Neonates with Perinatal asphyxia. J Neonatol. 2004;18(2):22-27. Available from: https://dx.doi.org/10.1177/0973217920040205.

4. Committee on Foetus and Newborn, American College of Obstetricians and Gynecologists and Committee on Obstetric 
Practice Pediatrics. Pediatrics. 1996;98(1):141-2.

5. Robertson CM, Perlman M. Follow-up of the term infant after hypoxic-ischemic encephalopathy. Paediatr Child Health. 2006;11(5):278-282.

6. Sarnat HB, Sarnat M. Neonatal encephalopathy following fetal distress: a clinical and electroencephalographic study. Arch Neurol. 1976;33(10):696-705. Available from: https://doi.org/ 10.1001/archneur.1976.00500100030012.

7. Gluckman PD, Wyatt JS, Azzopardi D, Ballard R, Edwards AD, Ferriero DM, et al. Selective head cooling with mild systemic hypothermia after neonatal encephalopathy: multicentre randomised trial. Lancet. 2005;365(9460):663-670. Available from: https://dx.doi.org/10.1016/s0140-6736(05)70932-6.

8. Lohan R, Chauhan G, Dalal A, Gupta SP, Bhardwaj AK, Ahlawat M. A Study on Incidence of Clinical Hypoxic Ischemic Encephalopathy Injury in Newborns with Perinatal Asphyxia. J Paediatr Child Health. 2016;1(1):1-4. Available from: https: //dx.doi.org/10.15226/2576-4802/1/1/00104.

9. Dalal EA, Bodar NL. A study on birth asphyxia at the tertiary health center. Natl J Med Res. 2013;3(4):374-376.

10. Akka P, Pallavi. Correlation of clinical variables with hypoxicischemic encephalopathy stages. MIJOMED. 2018;8(2):41-43. Available from: https://doi.org/10.26611/1014821.

11. Milsom I, Ladfors L, Thiringer K, Niklasson A, Odeback A, Thornberg E. Influence of maternal, obstetric and fetal risk factors on the prevalence of birth asphyxia at term in a Swedish urban population. Acta Obstet Gynecol Scand. 2002;81(10):909-917. Available from: https://doi.org/10. 1034/j.1600-0412.2002.811003.x.

12. Ziadeh SM, Sunna E. Obstetric and perinatal outcome of pregnancies with term labour and meconium-stained amniotic fluid. Archiv für Gynaekologie. 2000;264(2):84-87. Available from: https://dx.doi.org/10.1007/s004040000088.

13. Ash AK. Managing patients with meconium-stained amniotic fluid. Hosp Med. 2000;61(12):844-848. Available from: https: //dx.doi.org/10.12968/hosp.2000.61.12.1482.

14. Portman RJ, Carter BS, Gaylord MS, Murphy MG, Thieme RE, Merenstein GB. Predicting neonatal Morbidity after perinatal asphyxia: a scoring system. Am J Obstet Gynecol. 1990;192(1):174-81. Available from: https://doi.org/10.1016/ 0002-9378(90)90844-w.

15. Sykes GS, Molloy PM, Johnson P, Gu W, Ashworth F, Stirrat GM, et al. Do Apgar score indicate Asphyxia? Lancet. 1983;1(8270):494-500. Available from: https://doi.org/10. 1016/s0140-6736(82)91462-3.

16. Finer NN. Factors Affecting Outcome in Hypoxic-Ischemic Encephalopathy in Term Infants. Am J Dis Child . 1983;137(1):21-21. Available from: https://dx.doi.org/10. 1001/archpedi.1983.02140270017006.

Copyright: (C) the author(s), 2020. It is an open-access article distributed under the terms of the Creative Commons Attribution License (CC BY 4.0), which permits authors to retain ownership of the copyright for their content, and allow anyone to download, reuse, reprint, modify, distribute and/or copy the content as long as the original authors and source are cited.

How to cite this article: Sekhar MC. Correlation of Hypoxic Ischemic Encephalopathy Stages with Clinical Variables. Asian J. Clin. Pediatr. Neonatol. 2020;8(3):1-6.

DOI: dx.doi.org/10.47009/ajcpn.2020.8.3.1

Source of Support: Nil, Conflict of Interest: None declared. 